\title{
Cancer of the Oesophagus in Africa, Population Susceptibility, and Preventive Intervention: A Literature Review
}

\author{
Alastair M Sammon ${ }^{1}$ \\ ${ }^{1}$ Department of Human Biology, Walter Sisulu University, Mthatha, South Africa \\ Correspondence: Alastair Sammon, Department of Human Biology, Walter Sisulu University, Private Bag X1, \\ Mthatha, Eastern Cape 5100, South Africa.
}

Received: December 8, 2020 Accepted: January 7, 2021 Online Published: January 21, 2021

doi:10.5539/gjhs.v13n3p124 URL: https://doi.org/10.5539/gjhs.v13n3p124

\begin{abstract}
Squamous cancer of the oesophagus has been, for almost a century, a major cause of morbidity and mortality in East and Southern Africa, and has been referred to as endemic in many high-incidence regions. Uncertainty about aetiology has inhibited effective preventive initiatives.

The aims of this study are to assess why some African regions and countries have a very high incidence of oesophageal cancer; to assess evidence-based associations and risk factors for population susceptibility and for individual susceptibility; to identify which of these are amenable to change; to put forward possible strategies to achieve change.

A literature review identified the well-evidenced associations with high incidences of squamous oesophageal cancer to be maize, maize meal, and tobacco. A predominantly maize-based diet, and high use of maize meal are associated with population susceptibility. Tobacco is associated with individual susceptibility within a susceptible population. Alcohol, polycyclic aromatic hydrocarbons and wild vegetables are possible risk factors; other proposed risk factors are improbable.

Possible actions are discussed for countries where there is a very high incidence of squamous cancer of the oesophagus. Measures to reduce population susceptibility include regulation of commercially produced maize meal to reduce content of free fatty acids at the time of consumption and supplementation of the diet with omega-3 fatty acid. Fortification of maize meal with zinc and selenium, and health education about production and consumption of fruit and vegetables may be helpful.
\end{abstract}

Legislation to reduce tobacco consumption will reduce individual susceptibility.

Keywords: cancer, maize, oesophagus, prevention, susceptibility, tobacco

\section{Introduction}

Cancer of the oesophagus in Africa is predominantly squamous cell carcinoma (SCCO). The history of SCCO in Africa is of great differences in incidence between populations, and great differences over time within the same populations. Study of the history of the start of the epidemic phase of the disease, its growth and spread in South and East Africa, and comparisons with unaffected countries within the continent all indicate the presence of a factor or factors which have created population susceptibility. There are regions where the incidence is sustained at a very high level, and there the disease has been described as endemic.

Much of the research into the aetiology of SCCO in Africa has involved case-control and cohort studies within endemic areas. These are proven methods for pinpointing the reasons for individual susceptibility within an affected community, but may not provide insight into the reasons for population susceptibility.

Environmental risk factors may be associated with population susceptibility or with individual susceptibility. Based on evidenced risk factors and associations I discuss measures to reduce the incidence of SCCO in Africa.

\section{Method}

A literature search was carried out using Embase and Medline, using the words oesophageal or oesophagus, and squamous. They were used in combination with meta-analysis, Africa, cancer, carcinoma, tobacco, papillomavirus, alcohol, pylori, nitrosamine, polycyclic aromatic hydrocarbon, maize, fumonisin, wood, charcoal, diet, trace element, selenium, zinc, p53, and non-acid reflux. Duplicate articles and those with no reference to aetiology or 
prevention, or neither directly or indirectly relevant to the disease in Africa were excluded. References were included of other areas of the world with high incidences of SCCO, and with common dietary or environmental profiles, or with SCCO-targeted intervention. References within retrieved papers were followed as appropriate, and relevant archived material was added. The literature search provided 277 relevant papers, supplemented with 151 archived or cross-referenced papers (see Figure 1).

277 articles identified through database search

151 additional articles identified from other sources

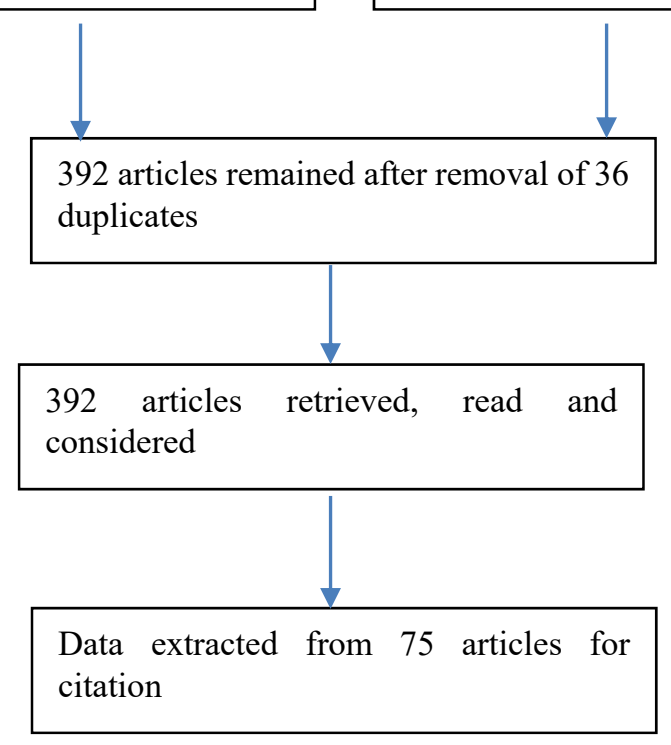

Figure 1. Literature search process

\section{Results}

\subsection{History}

Cancer of the oesophagus in Southern Africa was very rare until the fourth and fifth decades of the twentieth century (Macvicar, 1925; Berman, 1935) at which time there was a sudden rise in incidence. Hospitals in South Africa recorded 'a slowly increasing incidence in the Transkei since 1930, with an explosive rise after 1940' (E. Rose, 1979). Extensive field enquiries in Transkei region of the Eastern Cape of South Africa in 1961 recorded that the disease had been recognized by local people for about 25 years; prior to that it had been unknown (Burrell, 1962). Oettle, Paterson, Lieman and Segal (1986) depicted a high incidence of oesophageal cancer as beginning in the Eastern Cape of South Africa in 1946 and spreading North and East through East and Central Africa. It was at that time described as an epidemic (Bradshaw, McGlashan, \& Harington, 1983) because of both the speed of increase of incidence and the apparent geographical spread that was observed. The incidence in some areas has been remarkably high. In Transkei in the Eastern Cape it was estimated that $20 \%$ of men would be affected by the age of 75 years in the absence of other causes of death (van Rensburg, 1979). A rise of more than $600 \%$ was observed in Transkei in the years 1950 to 1965 (E. Rose, 1979). The incidence in the Eastern Cape of South Africa is now falling (Somdyala, Parkin, Sithole, \& Bradshaw, 2014). The highest African incidences of the disease are currently in Kenya (21.5/100 000 males) and Malawi (22.1/100 000 males) (Globocan, 2018).

\subsection{Causation Theories}

There are two categories of causation theory: firstly that there is one potent carcinogen, present in significant amounts in areas of high incidence of SCCO. This category of theories has included illicit alcoholic brews (Burrell, 1957); fumonisins (Marasas, 2001); carcinogens in maize beer (Bradshaw, McGlashan, \& Harington, 1983); and human papillomavirus (Matsha et al., 2007). Comprehensive and sustained attempts by researchers to find credible and consistent evidence against any of these, or any other substance, as the single powerful carcinogen have been unsuccessful (Sammon \& Ndebia, 2019). 
The second group of theories blames nutritional deficiencies and 'ordinary' carcinogens. This category combines the deficiencies of a maize diet with known environmental carcinogens such as tobacco, PAH, and nitrosamines (van Rensburg, 1981; E. Rose, 1979).

The approach that co-researchers and I have taken is similar to the second group of theories, but in addition cites as the major promoting factor the effect of degenerative change in the chemical content of milled maize (Sammon \& Iputo, 2006). The inclusion of maize meal in the causation of SCCO is not common in aetiological reviews. A body of evidence is presented in section 3.4.

\subsection{Categories of Associations and Risks}

There is a hierarchy of associations and risks which can be categorised as reliable, uncertain, or improbable. This categorisation relates to the possibility that any one association might contribute significantly to either mass population susceptibility or to individual susceptibility to SCCO (see Table 1). Reliable associations are those where repeated evidence is available from the study of the history and demography of the disease, analysis of diet and foodstuffs, and case-control or cohort studies. Uncertain associations are those where there is limited or equivocal evidence. Improbable associations are with substances which have been raised as possible aetiological agents, but have subsequently had evidence found to discredit them, where relatively weak circumstantial evidence only is available, or where no significant evidence has been put forward (Sammon \& Ndebia, 2019).

Table 1. Hierarchy of associations with SCCO

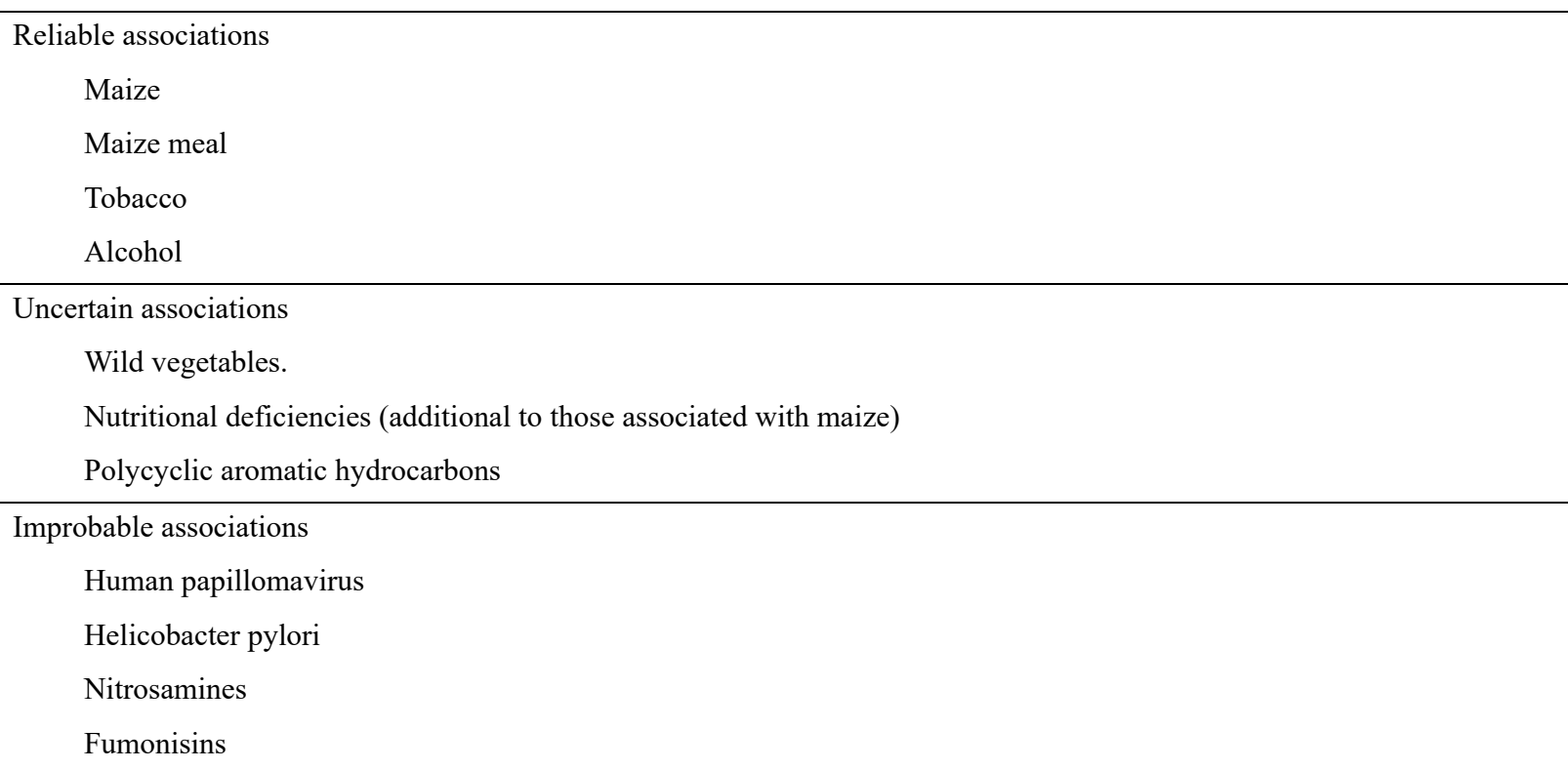

This categorisation relates to the possibility that any one association might contribute significantly to either mass population susceptibility or to individual susceptibility to SCCO. Summarised from Sammon and Ndebia (2019).

\subsection{Reliable Associations}

\subsubsection{Maize}

Reliance on maize has been a constant feature throughout Africa in areas of very high incidence of SCCO. Early studies found that high levels of SCCO in Africa have in every case been associated with relative poverty and with the use of maize as the principal agricultural crop and source of calories (Cook, 1971; van Rensburg, 1981). This remains the case in the twenty-first century.

The use in Africa of maize as a major dietary component greatly predates the sudden and rapid growth of SCCO. Maize was first grown in Africa in the sixteenth century. By the nineteenth century maize and sorghum were the dominant crops in South Africa. The later decades of the nineteenth century saw heavy dependence on maize, particularly in South Africa. It is of note that during this period the incidence of SCCO remained very low. During the first three decades of the twentieth century maize became the major subsistence crop in South Africa; by 1960 it was the major crop in Rhodesia (Zimbabwe and Zambia), Kenya, and Malawi (McCann, 2005). 
The incidence of SCCO rose rapidly from rare to epidemic levels at the same time that milling of maize became easily available to rural subsistence farmers. The rise of SCCO was recorded as beginning in the Ciskei/Transkei border of the Eastern Cape of South Africa in the fourth and fifth decades of the $20^{\text {th }}$ century. This coincided with the manufacture and distribution in the early 1930s of small-scale milling machines to rural trading stores in the same area (Sammon, 2009). There is therefore a historical reason to associate SCCO more with commercially milled maize than with whole maize. Prior to the 1930s, ground maize was a part of the traditional diet, prepared at home using grinding stones, and used within a day or two of grinding. With the availability of local machine milling, larger quantities of maize were now carried to local stores, milled and taken home to be used over the course of days, weeks or even months. Two studies, both in Natal, South Africa, found that the highest risk group for SCCO were rural people with a little education and some cash income. This is a group who would have the ability to buy maize meal, or to pay to have their own maize ground at a local store. (Bradshaw \& Schonland, 1969; van Rensburg, E. Bradshaw, D. Bradshaw, \& E. Rose, 1985). Followed historically, the availability of commercially milled maize began geographically where the 'epidemic' was first observed in the Transkei and Ciskei regions of the Eastern Cape of South Africa, and appeared to spread Northwards (Keen, 1971; Oettle et al., 1986). The incidence of SCCO is now reducing in SA (Somdyala et al., 2014; Globocan, 2018) coincident with and possibly related to less rural poverty and greater choices of diet. SCCO has its African epicentre currently in Malawi where there is much poverty, little variation of available and affordable diet and a continued progressive adoption of milled maize products as the principal dietary components.

There are 4 relevant studies concerning consumption of milled maize, 2 in Africa and 2 in Italy. All are case-control studies. In South Africa van Rensburg et al (1985) found that daily against weekly consumption of bought maize meal had a relative risk of 5.7 (3.09-10.63) for oesophageal cancer. In Malawi Mlombe et al. (2015) calculated an OR of $6.6(2.3-19.3)$ for those consuming the most refined maize meal against those consuming less refined types. In Italy Rossi et al (1982) found that high versus low daily quantity of maize flour consumed carried a relative risk of $6.17(2.96-12.89)$. Also in North-Eastern Italy, where maize is eaten in the form of polenta made from maize flour, Franceschi, Bidoli, Baron and La Vecchia (1990), showed an odds ratio of 2.8 (1.5 - 5.1) for high versus low number of servings per week of maize. These studies, two from endemic areas for SCCO, and two from non-endemic areas strongly support the contention that it is not maize itself, but maize meal which is a major risk factor. For this to be the case there requires to be a significant difference between whole maize and maize meal. Possible non-spurious reasons for the association with commercially ground maize meal are contamination, chemical degeneration, and nutritional deficiencies.

\subsubsection{Contamination of Maize}

Before the process of refining, poor storage of whole maize may result in contamination with fungi and with fungal mycotoxins including Fumonisin B1. This contamination is not specific to maize meal, but applies to all maize and maize products (Misahairabgwi, Ezekiel, Sulyok, Shephard, \& Krska, 2017; Chauhan, Washe, \& Minota, 2016) and is not greater in maize meal or maize meal products than in whole maize. There is no apparent difference in contamination between whole maize and maize meal.

\subsubsection{Chemical Degeneration of Maize Meal}

Carefully stored whole maize seeds undergo chemical degeneration slowly if at all. Degeneration occurs rapidly in milled maize. It is encouraged by, but not dependent on warmth and moisture.

Milling significantly reduces the lipid and vitamin content, and also destroys the architecture of the seeds, mixing lipids with lipases. Mixing of lipids and lipases initiates de-esterification of complex fatty acids to free fatty acids. The fats in whole maize are held as triglycerides and the free fatty acid content is negligible. Milled maize has been shown to contain up to $42 \%$ of its fat as free fatty acids (FFAs) (Sammon, 1999) compared to less than 1\% in whole maize (Webber, 1969). This process begins immediately on milling and progresses over months with steadily increasing release of FFAs (Sammon \& Whittington, 2009). (See Figure 2) 


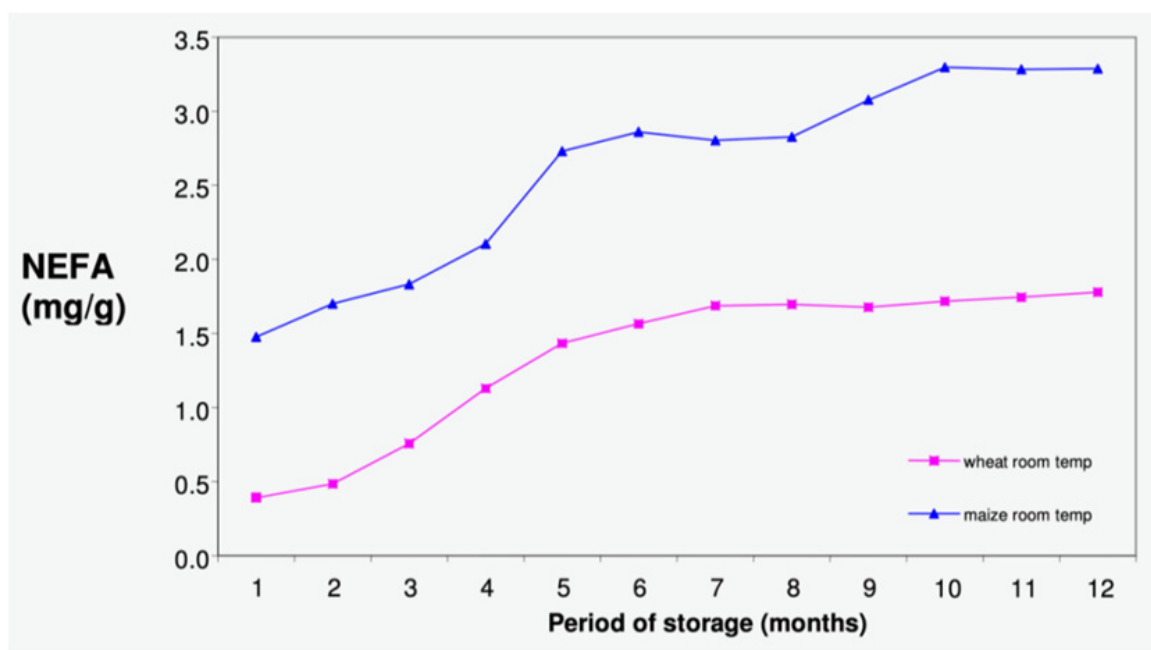

Figure 2. Non-esterified fatty acids (NEFA) in milled maize and wheat (Adapted from Sammon \& Whitington, (2009)

Compared with sorghum and millet which rapidly become rancid after milling, in maize meal the further process of breakdown of FFAs by oxidation and the onset of the unpleasant taste change of rancidity are late and slow. Maize meal may thus undergo very significant chemical degeneration before any taste consequences are perceived and the maize meal discarded.

The omega 6: Omega 3 ratio in maize is usually over 70:1. For some communities whose diet is almost exclusively maize meal-based this may be the major, and for some the almost exclusive source of fatty acids.

Unlike whole maize, which has negligible free fatty acid, consumption of degenerating milled maize presents a significant amount of non-esterified linoleic acid to the stomach. $300 \mathrm{~g}$ of maize, milled three months previously, and consumed during the course of one day, may supply a daily intake of around $327 \mathrm{mg}$ of non-esterified linoleic acid (Sammon \& Whitington, 2009). Triglyceride is not locally metabolised in the stomach, whereas free fatty acid is able to be metabolised in the gastric mucosa. The lack of other dietary fatty acids, particularly omega-3 fatty acids, facilitates conversion of free linoleic acid to arachidonic acid and then to prostaglandin E2 in the stomach mucosa (Doyle, Nemeth, Skoglund, \& Mandel, 1989). PGE2 has physiological actions in the stomach both as an acid suppressant and a facilitator of gastro-oesophageal reflux (Mukopadhyay, Rattan, \& Goyal, 1975; Goyal, Rattan, \& Hersh, 1973). We have proposed that non-acid reflux resulting from this combination of acid suppression and gastro-oesophageal reflux is the major aetiological factor for SCCO (Sammon, 2009). Supporting evidence for these steps is available: Pink showed elevated levels of PGE2 in gastric fluid from an at-risk community in Transkei (Pink et al., 2011); a study in that community found that fasting gastric $\mathrm{pH}$ was over 4 in half the population, and that a high gastric $\mathrm{pH}$ was associated with increased frequency of maize consumption (Sammon, Mguni, Mapele, Awotedu, \& Iputo, 2003); non-acid gastro-oesophageal reflux has been shown to be abnormally prevalent in the same high-risk community (Ndebia, Sammon, Umapathy, \& Iputo, 2015); there is evidence that profound gastric hypochlorhydria is a strong risk factor for SCCO; OR 6(1.9-18.4) (Iijima et al., 2009), and studies from South Africa and from Japan that non-acid reflux is associated with SCCO; Uno et al. (2011) carried out 24-hour $\mathrm{pH} / \mathrm{impedance}$ studies on 14 patients with superficial SCCO and 14 controls. The patients had an average of 46.5 episodes of non-acid reflux, and the controls 24.5 ( $\mathrm{P}=0.012)$. Kgomo, Mokoena and Ker (2017) reported an OR of 8.8 (3.2-24.5) of developing SCCO for those with predominantly non-acid reflux.

There are two relevant studies, both well-controlled but with potential confounding, reporting an association of consumption of other dietary fats with lower risk of SCCO: van Rensburg's case-control study in 1985 (van Rensburg et al., 1985) found a RR of 0.51(0.37-0.69) for those using butter or margarine daily. Another case-control study (Sammon, 1992) found that SCCO cases consumed significantly less bought fat (margarine, cooking fat and oil) than controls ( $\mathrm{P}=0.03)$.

\subsubsection{Nutritional Deficiencies}

Maize contains essential fats and micronutrients including vitamins and trace elements. Milling reduces the amounts of all of these (Gwirtz \& Garcia-Casal, 2013). Selenium and zinc are the two elements whose deficiency 
is most associated with SCCO in ecological and community studies (Schaafsma et al., 2015; Burrell, Roach, \& Shadwell, 1966; van Rensburg, 1981; Kibblewhite, van Rensburg, Laker, \& E. Rose, 1984), in case-control studies (Mark et al., 2000; Lu et al., 2006) and in a cohort study (Abnet et al., 2005). The General Population Trial involving nearly 30,000 people in Linxian, China, used four different combinations of vitamins and trace elements including riboflavin, vitamin E, selenium and zinc, given over 5.25 years. 10 years after the intervention, there was no significant reduction in SCCO for the overall population in any of the treatment groups (Qiao et al., 2009). A comprehensive review by Kamangar et al., (2009) concluded that 'most vitamins and minerals do not change (SCCO) risk. However intake of selenium in selenium-deficient populations may decrease EC risk, especially in younger people'.

Many studies have shown a reduction of SCCO incidence associated with increased fruit and vegetable intake (Yang et al., 2005, [China]; Freedman, Abnet et al., 2007 [USA]; Yamaji et al., 2008 [Japan]; Sewram, Setas, O'Connell \& Myers, 2014 [South Africa]). A meta-analysis by Wang et al., (2015) on the effect of vitamin C on SCCO incidence found an OR of $0.63(0.52-0.75)$ for highest versus lowest intake of citrus fruit. No studies from Africa were included. Li et al (1989) in a case-control study in Linxian, China, found no association with intake of fruit and vegetables. A meta-analysis by Liu, Wang, Leng, and Changxing (2013) included case-control and cohort studies. This meta-analysis involved studies worldwide, but not including any from Africa. It was not focussed on high-incidence areas for SCCO. Liu et al cautiously concluded that vegetables and fruit may significantly reduce the risk of SCCO. While acknowledging this, The World Cancer Research Fund /American Institute for Cancer Research assessment in 2016 concluded that the evidence suggesting that greater consumption of fruit and vegetables decreases the risk of oesophageal squamous cell carcinoma is limited.

\subsubsection{Evaluation}

Using maize as the staple diet is associated with SCCO. The use of maize meal is associated with SCCO. The evidence available supports the contention that not only are maize and maize meal risk factors, but that the association is causal.

The deficiencies of maize, especially a maize-meal diet, combined with the use of degenerating maize meal are candidates for causing the population susceptibility found in endemic areas.

Low trace elements, specifically zinc and selenium, have an association with SCCO. This is not proven to be causal. Supplementation with these two elements may bring marginal improvement only.

It is probable that consumption of fruit and vegetables is a protective factor in SCCO incidence. The magnitude of this effect is uncertain.

\subsubsection{Tobacco}

Tobacco is well-evidenced as an oesophageal carcinogen for SCCO in rich and poor communities throughout the world. It is an established risk factor in areas of low, medium and high incidence. Use of tobacco brings with it a relative risk for SCCO of 1.32 up to 18.8. In high-incidence areas of Africa it has been shown to be a risk factor in many studies (Sammon \& Ndebia, 2019). It is chewed, consumed as cigarettes, and smoked in pipes. All studies and nearly all theories of causation include tobacco as a significant carcinogenic component of SCCO. The amount of tobacco consumed by those who contract SCCO in high incidence areas is often low (Segal, Reinach, \& de Beer, 1988; van Rensburg et al., 1985). Twenty to thirty percent of SCCO sufferers in endemic areas do not use tobacco, so that the incidence of SCCO even in non-smokers is very high (Sewram, Sitas, O'Connell, \& Myers, 2016; Parkin et al., 1994; van Rensburg et al., 1985).

\subsubsection{Evaluation}

Tobacco is a highly significant risk factor for individuals.

\subsubsection{Alcohol}

Alcohol is a well-evidenced risk factor in studies in medium and low-incidence areas for SCCO throughout the world (Sammon \& Ndebia, 2019), and there is evidence of a synergistic effect with tobacco. In communities in Africa with a very high incidence of SCCO, the evidence for alcohol as a major risk factor is mixed. In studies from the high-incidence areas of China and Iran, the great majority of those suffering from SCCO did not consume alcohol (Li et al., 1989, Joint Iran-International Agency for research on Cancer Study Group, 1977). Most studies have failed to find a proven role for alcohol in high-risk areas of Africa (Matsha et al., 2006; Parkin, Vizcaino, Skinner, \& Ndhlovu, 1994; Sammon, 1992; van Rensburg et al., 1985). One study by Sewram et al. (2016) did find an association with SCCO in a high incidence area.

Evaluation: Alcohol has an undoubted role worldwide in oesophageal carcinogenesis, but its role in endemic areas 
for SCCO in Africa is not established.

\subsection{Uncertain Associations}

\subsubsection{Wild Vegetables}

It is possible that wild vegetables may be aetiologically involved in some areas of high incidence. There are two studies which provide evidence against Garden Nightshade - Solanum nigrum. This is used as a pot herb in some rural areas of South Africa. One of its known effects is to reduce gastric output of acid and pepsin (Akhtar \& Munir, 1989). Purchase, Tustin and van Rensburg (1975) fed rats with a diet including Solanum nigrum and Sonchus oleraceus, and found epithelial dysplasia of the oesophagus. In the Eastern Cape of South Africa a case-control study in 1992 found that consumption of S nigrum carried with it a relative risk of 3.6 (1.40-9.33) for SCCO (Sammon, 1992). E. Rose (1982) records that Solanum nigrum was commonly used in the high incidence area of Transkei, but not in the low incidence area. This herb is not used throughout endemic regions and countries. Sewram, Sitas, O'Connell and Myers (2014), also working in the Eastern Cape of South Africa, found that eating wild vegetables (these were not individually identified) carried a significant risk for SCCO (OR for males 1.76; for females 2.4). These papers provided significant evidence only in one geographical region.

\subsubsection{Evaluation}

Wild vegetables, particularly $\mathrm{S}$ nigrum may be risk factors for individuals.

\subsubsection{Polycyclic Aromatic Hydrocarbons (PAH)}

Polycyclic aromatic hydrocarbons are common in foods, tobacco and smoke from incomplete combustion of fossil fuel. A major source of PAH is tobacco. PAH are known carcinogens to lung, breast, pancreas, and bladder (Roshandel, Semnani, Malekzadeh, \& Dawsey, 2012). High levels of PAH have been found in high-risk areas for SCCO in China (Roth et al., 1998), Iran (Kamangar et al., 2005; Islami et al., 2012), and Kenya (Pritchett et al., 2017).

In Zambia Kayamba et al. (2015) found a significant association between charcoal or firewood cooking and SCCO. Their study was matched for age and sex. Dandara, Li, Walther and Parker (2006) working in Cape Town matched their controls for age and geographic location and again found a strong association between SCCO and using wood or charcoal in the home. Pacella-Norman et al. (2002) in Johannesburg, South Africa found no association. The use of firewood and charcoal in Africa is not limited to endemic areas for SCCO, and was widely prevalent before the start of the epidemic phase of the disease. Charcoal and firewood cooking may be indicators of lifestyle, income and rural/urban living, and there is the possibility of confounding in these studies. In Kenya and Malawi, where SCCO is the nationally the third commonest cancer, lung cancer is respectively $17^{\text {th }}$ and $15^{\text {th }}$ most common cancer. This is difficult to understand if PAH is a major, or the major environmental carcinogenic factor for SCCO, in view of its much better-established association with lung cancer.

\subsubsection{Evaluation}

It is possible that PAH from wood and charcoal fires are carcinogenic factors. It may be a factor for individual susceptibility in endemic areas.

\subsection{Improbable Associations}

Fumonisins

Human papillomavirus

Helicobacter pylori

Nitrosamines

These factors are not dismissed lightly, but after consideration of the available evidence (Sammon \& Ndebia, 2019). Research so far has not provided adequate evidence of significant involvement of any of these in oesophageal carcinogenesis in endemic areas.

\section{Discussion}

\subsection{Determinants of Incidence}

G. Rose (1985) pointed out that 'the determinants of incidence are not necessarily the same as the cause of cases'. Much recent research into the aetiology of SCCO in Africa has been structured in a way that assesses the causes of cases. Case-control studies within affected communities are poor tools for identifying a shared influence on a whole community which creates a shared susceptibility. In seeking to understand the aetiology of high incidence of SCCO in Africa and to reduce it, a central component is the identification of causes of population susceptibility. 
The causes of cases and the determinants of incidence may coincide in some diseases. The presence of a powerful carcinogen geographically limited to the affected areas would achieve this for endemic SCCO. This kind of powerful carcinogen has been diligently sought, but not found for endemic SCCO in Africa. Carcinogens are present, and some including tobacco and (at a lower level of proof) alcohol, PAH and wild vegetables have been statistically associated with SCCO. Tobacco is a cause of cases, and alcohol, PAH and wild vegetables are possible causes of cases, but none of these is geographically limited to endemic areas, or consumed or present in the environment in overwhelming quantities in all endemic areas compared with non-affected areas. They are not supportable as significant causes of population susceptibility.

\subsection{Maize and Maize Meal}

Nutritional deficiencies of a maize diet combined with heavy consumption of maize meal, are universal in East African countries where SCCO is endemic, and there is no country within Africa which has this same level of dependence on maize and maize meal which does not have a high incidence of SCCO.

Maize as the predominant crop and source of calories is not sufficient on its own to cause high levels of SCCO - it did not do so in the late nineteenth and early twentieth centuries when it was so dominant in South Africa, but it remains one of the strongest population associations with SCCO. Usage of maize as maize meal, however, is an essential feature of all African populations with endemic SCCO.

Endemic levels of SCCO occur in other regions of the world where maize is not used. This does not diminish the thrust of the evidence against maize meal in Africa. All high-incidence areas of the world have in common reliance on a monotonous carbohydrate staple diet (E. Rose, 1978).

The nutritional deficiencies of maize, accentuated in maize meal, have been tackled in many countries by legislation mandating mineral and vitamin supplementation of all commercially milled maize. For both zinc and selenium there is evidence that deficiency is associated with SCCO. Supplementation may reduce the incidence but no such supplementation regime has brought dramatic results This applies also to an increase in consumption of fruit and vegetables, the effect of which is both uncertain and unquantified.

If it is accepted that the principal problem lies with physiologically active free fatty acids in maize meal, then action is required either to reduce exposure of consumers to these free fatty acids in maize meal, or to reduce their effect in the body.

\subsection{A Perishable Food}

Maize meal is a perishable food with a limited safe shelf life. Control of the period between milling and consumption will reduce to some extent but not eliminate the exposure of the consumer to excess free fatty acids since there is a physiologically significant amount of free linoleic acid in maize meal within a short time of milling. Limiting the maximum retail pack size to what can reasonably be used by a family within a few days would contribute to this by reducing average milling-to-consumption time.

Chemical or other methods of preventing the rapid hydrolysis of triglycerides after milling could be effective. Identification of methods of achieving this could be followed by legislation governing the amount of FFA at point of sale. A different strategy would be to set commercial producers a target level of FFA at point of sale, and thus oblige them to find a method of achieving this.

An alternative or additional approach is to find dietary methods of reducing the effect of FFA in the stomach. The adequate provision of other fats in the diet could achieve this. Measures to facilitate the availability and affordability of fish, nuts, and other dietary sources of omega-3 could contribute to this, but variety of diet is not usually available to the very poor. Supplementation of all maize meal with omega -3 fatty acid would be a perfect way to target those most at risk. Cost is an issue. Avoidance of any noticeable change in taste would be important for success.

Legislation for a minimum content of Omega-3 fat in all margarines and spreads would be easy to enact, but would not directly target the highest at-risk group.

\subsection{Other Measures}

Taxation and legislation aimed at reducing tobacco consumption has been successful in many countries, and could be applied in those countries where this is not yet the case.

Spending effort on health education to communities to encourage reduced exposure to alcohol, PAH and wild vegetables requires to be based on better evidence than is currently available. The effect of this kind of intervention is uncertain, possibly negligible. 
Although the value of promotion of vegetable and fruit production and consumption is not fully quantified as a preventive measure for SCCO, it has such clear benefits for general health that it may be worthwhile to include it as part of a strategy.

\subsection{Proposals}

I have listed proposed actions in Table 2.

Table 2. Proposals for Interventions

\begin{tabular}{ll}
\hline Maize meal & time from milling to sale \\
Regulate: & $\begin{array}{l}\text { time from milling to date of safe consumption } \\
\text { maximum size of retailed unit of maize meal } \\
\text { maximum permissible level of FFA in maize meal at point of sale }\end{array}$ \\
\hline Supplement & retailed maize meal with selenium and zinc \\
\hline Supplement & maize meal with omega-3 fatty acid \\
\hline Health education messages \\
\hline Promote & production and consumption of fruit and vegetables \\
\hline Tobacco & avoidance of S nigrum in appropriate communities \\
Legislate & proven ways of reducing tobacco usage \\
\hline Research & preventing hydrolysis of triglycerides in milled cereal. \\
Methods of & supplementing maize meal with omega-3 fatty acids \\
\hline
\end{tabular}

\section{Conclusions}

\subsection{Regional High Incidences}

Dietary factors determine which countries have a very high incidence of SCCO. Mineral deficiencies of a maize-based diet, and rapid chemical degeneration of maize meal are the best-evidenced causes of population susceptibility in endemic areas for SCCO. Tobacco is a well-established individual risk factor.

\subsection{Areas for Intervention}

Dietary mineral deficiencies; exposure to the content of degenerating maize meal, and tobacco usage are all amenable to intervention.

\subsection{Interventions}

Measures to reduce exposure of consumers of maize meal to products of degeneration include chemical methods to reduce hydrolysis of fatty acids after milling, and regulation to control free fatty acid content at point of sale, and to control the time from milling to consumption.

Continuation of appropriate supplementation of maize meal is likely to make a limited contribution. Health education messages about oesophageal cancer should be limited to proven associations.

Tobacco is the best-evidenced cause of individual susceptibility and appropriate legislation should be directed at reducing tobacco usage.

\section{Competing Interests Statement}

The authors declare that there are no competing or potential conflicts of interest.

\section{References}

Abnet, C. C., Lai, B., Qiao, Y.-L., Vogt, S., Luo, X.-M., Taylor, P. R., ... Dawsey, S. M.(2005). Zinc concentration in esophageal biopsy specimens measured by X-ray fluorescence and esophageal cancer risk. J Natl Cancer Inst., 97(4), 301-306. https://doi.org/10.1093/jnci/dji042

Akhtar, M. S., \& Munir, M. (1989). Evaluation of the gastric antiulcerogenic effects of Solanum nigrum, Brassica 
oleracea and Ocimum basilicum in rats. $J$ Ethnoparmacol, 27(1-2), 163-176 https://doi.org/10.1016/0378-8741(89)90088-3

Berman, C. (1935). Malignant diseases in the Bantu of Johannesburg and the Witwatersrand gold mines. S Afr J Med Sci., 1, 12-30.

Bradshaw, E., \& Schonland, M. (1969). Esophageal and lung cancers in Natal African males in relation to certain socio-economic factors. Br J Cancer, 23, 275-284. https://doi.org/10.1038/bjc.1969.37

Bradshaw, E., McGlashan, N. D., \& Harington, J. S. (1983). Oesophageal cancer: smoking and drinking in Transkei. Occasional paper number 27, Institute of Social and Economic Research, Rhodes University, Grahamstown, South Africa.

Burrell, R. J. W. (1957). Oesophageal cancer in the Bantu. S Afr Med J., 31, 401-409.

Burrell, R. J. W. (1962). Esophageal cancer among Bantu in the Transkei. J Natl Cancer Inst, 28, 495-514 https://doi.org/10.1093/jnci/28.3.495

Chauhan, N. M., Washe, A. P., \& Minota, T. (2016) Fungal infection and aflatoxin contamination in maize collected from Gedeo zone, Ethiopia. Springerplus, 5, 73. https://doi.org/10.1186/s40064-016-2485-x

Cook, P. (1971). Cancer of the oesophagus in Africa. $\mathrm{Br} J$ Cancer, 25, 853-878. https://doi.org/10.1038/bjc.1971.99

Cook, P., \& Burkitt, D. P. (1971). Cancer in Africa. $B r$ Med Bull., 27(1), 14-20. https://doi.org/10.1093/oxfordjournals.bmb.a070807

Dandara, C., Li, D. P., Walther, G., \& Parker, M. I. (2006). Gene-environment interaction: the role of SULT1A1 and CYP3A5 polymorphisms as risk modifiers for squamous cell carcinoma of the oesophagus. Carcinogenesis, 27(4), 791-797. https://doi.org/10.1093/carcin/bgi257

Doyle, M. J., Nemeth, P. R., Skoglund, M. L., \& Mandel, K. G. (1989). In vivo assessment of precursor-induced prostaglandin release within the rat gastric lumen. Prostaglandins, 38(5), 581-97 https://doi.org/10.1016/0090-6980(89)90151-2

Franceschi, S., Bidoli, E., Baron, A. E., \& La Vecchia, C. (1990). Maize and risk of cancers of the oral cavity, pharynx, and esophagus in Northeastern Italy. $J$ Natl Cancer Inst., 82(17), 1407-1411. https://doi.org/10.1093/jnci/82.17.1407

Freedman, N. D., Abnet, C. C., Leitzmann, F., Mouw, T., Subar, A. F., Hollenbeck, A. R., \& Schatzkin, A. (2007). A prospective study of tobacco, alcohol, and the risk of esophageal and gastric cancer subtypes. Amer $J$ Epidemiol, 165(12), 1424-1433. https://doi.org/10.1093/aje/kwm051

Freedman, N. D., Park, Y., Subar, A. F., Hollenbeck, A. R., Leitzmann, M. F., Schatzkin, A., \& Abnet, C. C. (2007). Fruit and vegetable intake and esophageal cancer in a large prospective cohort study. Int J Cancer, 121(12), 2753-2760. https://doi.org/10.1002/ijc.22993

Goyal, R. K., Rattan S., \& Hersh T. (1973). Comparison of the effects of prostaglandin E1, E2 and A2 and of hypovolemic tension on the lower esophageal sphincter. Gastroenterology, 65, 608-12. https://doi.org/10.1016/S0016-5085(19)33040-9

Gwirtz, J. A. \& Garcia-Casal, M. N. (2013). Processing maize flour and corn meal food products. Annals of the New York Academy of Sciences, 1312, 66-75. https://doi.org/10.1111/nyas.12299

Iijima, K., Koike, T., Abe, Y., Yamagishi, H., Ara, N., Asanuma, K., ... Shimosegawa, T. (2010). Gastric hyposecretion in esophageal squamous-cell carcinomas. Dig Dis Sci., 55, 1349-1355. https://doi.org/10.1007/s10620-009-0853-x

Islami, F., Boffetta, P., van Schooten, F. J., Strickland, P., Phillips, D. H., Pourshams, ... Malekzadeh, R. (2012). Exposure to polycyclic aromatic hydrocarbons among never smokers in Golestan Province, Iran, an area of high incidence of esophageal cancer - a cross-sectional study with repeated measurement of urinary 1-OHPG in two seasons. Frontiers in Oncology, Feb(2), article 14. https://doi.org/10.3389/fonc.2012.00014

Joint Iran-International Agency for Research on Cancer Study Group. (1977). Esophageal cancer studies in the Caspian Littoral of Iran: Results of population studies - A prodrome. J Natl Cancer Inst, 59(4), 1127-1138 https://doi.org/10.1093/jnci/59.4.1127

Kamangar, F., Strickland, P. T., Pourshams, A., Malekzadeh, R., Boffetta, P., Roth, M. J., .. Dawsey, S. M. (2005). Anticancer Res, 25, 425-428. 
Kayamba, V., Sinkala, E., Mwanamakondo, S., Soko, R., Kawimbe, B., Amadi, B., ... Kelly, P. (2015). Trends in gastrointestinal diagnosis over four decades in Lusaka, Zambia: a retrospective analysis of endoscopic findings. BMC Gastroenterology, 15, 127. https://doi.org/10.1186/s12876-015-0353-8

Keen, P. (1971). The epidemiology of oesophageal cancer in SA. In Silber (ed.), Carcinoma of the oesophagus. Balkema Cape Town.

Kgomo, M., Mokoena, T. R., \& Ker, J. A. (2017). Non-acid gastro-oesophageal reflux is associated with squamous cell carcinoma of the oesophagus. BMJ Open Gastroenterol, 4, e000180. https://doi.org/10.1136/bmjgast-2017-000180

Kibblewhite, M. G., van Rensburg, S. J., Laker, M. C., \& Rose, E. F. (1984). Evidence for an intimate geochemical factor in the etiology of esophageal cancer. Environ Res., 33(2), 370-378. https://doi.org/10.1016/0013-9351(84)90035-5

Li, J.-Y., Ershow, A. G., Chen, Z.-J., Wacholder, S., Li, G.-Y., Guo, W., ... Blot, W. J. (1989). A case-control study of cancer of the esophagus and gastric cardia in Linxian. Int $J$ Cancer, 43, 755-761. https://doi.org/10.1002/ijc.2910430502

Liu, J., Wang, J., Leng, Y., \& Changxing L. V. (2013). Intake of fruit and vegetables and risk of esophageal squamous cell carcinoma: A meta-analysis of observational studies. Int $J$ Cancer, 133, 473-486. https://doi.org/10.1002/ijc.28024

Lu, H., Cai, L., Mu, L. N., Lu, Q. Y., Zhao, J., Cui, Y., ... Zhang, Z. F. (2006). Dietary mineral and trace element intake and squamous cell carcinoma of the esophagus in a Chinese population. Nutr Cancer, 55(1), 63-70. https://doi.org/10.1207/s15327914nc5501_8

Macvicar, N. (1925). Notes on cancer among the native people. S Afr Med Rec, 23, 315.

Marasas, W. F. (2001). Discovery and occurrence of the fumonisins: a historical perspective. Environ health Perspect., 109(Suppl), 2, 239-243. https://doi.org/10.1289/ehp.01109s2239

Mark, S. D., Qiao, Y.-L., Dawsey, S. M., Wu, Y.-P., Katki, H., Gunter, E. W., ... Taylor, P. R. (2000). Prospective study of serum selenium levels and incident esophageal and gastric cancers. $J$ Natl Cancer Inst., 92(21), 1753-1763. https://doi.org/10.1093/jnci/92.21.1753

Matsha, T., Brink, L., van Rensburg, S., Hon, D., Lombard, C., \& Erasmus, R. (2006). Traditional home-brewed beer consumption and iron status in patients with esophageal cancer and healthy control subjects from Transkei, South Africa. Nutr Cancer, 56(1), 67-73. https://doi.org/10.1207/s15327914nc5601_9

Matsha, T., Donninger, H., Erasmus, R. T., Hendricks, D., Stepien, A., \& Parker, M. I. (2007). Expression of p53 and its homolog, p73, in HPV DNA positive oesophageal squamous cell carcinomas. Virology, 369, 182-190. https://doi.org/10.1016/j.virol.2007.07.025

Misihairabgwi, J. M., Ezekiel C. N., Sulyok, M., Shephard, G. S., \& Krska, R. (2019). Mycotoxin contamination of foods in Southern Africa: A 10-year review (2007-2016). Crit Rev Food Sci Nutr, 59(1), 43-58. https://doi.org/10.1080/10408398.2017.1357003

Mlombe, Y. B., Rosenberg, N. E., Wolf, L. L., Dzamalala, C. P., Chalulu, K., Chisi, J., ... Shores, C. G. (2015). Environmental risk factors for oesophageal cancer in Malawi: A case-control study. Malawi Med J., 27(3), 88-92. https://doi.org/10.4314/mmj.v27i3.3

Mukhopadhyay, A., Rattan, S., \& Goyal, L. K. (1975). Effect of prostaglandin E2 on esophageal motility in man. $J$ Appl Physiol, 39(3), 479-81. https://doi.org/10.1152/jappl.1975.39.3.479

Ndebia, E. J., Sammon, A. M., Umapathy, E., \& Iputo, E. J. (2015). Normal values of 24-hour ambulatory impedance-pH monitoring in a rural South African cohort of healthy participants. Dis Oesophagus, 4, 385-391. https://doi.org/10.1111/dote.12333

Oettle, G. J., Paterson, A. C., Leiman, G., \& Segal, I. (1986). Esophagitis in a population at risk for esophageal carcinoma. 57, 2222-2229. https://doi.org/10.1002/1097-0142(19860601)57:11<2222::AIDCNCR2820571125>3.0.CO;2-3

Pacella-Norman, R., Urban, M. I., Sitas, F., Carrara, H., Sur, R., ... Beral, V. (2002). Risk factors for oesophageal, lung, oral and laryngeal cancers in black South Africans. $\mathrm{Br} J$ Cancer, 86, 1751-1756. https://doi.org/10.1038/sj.bjc.6600338

Parkin, D. M., Vizcaino, A. P., Skinner, M. E. G., \& Ndhlovu, A. (1994). Cancer patterns and risk factors in the 
African population of Southwestern Zimbabwe, 1963-77. Cancer Epidemiol Biomarkers Prev., 3, 537-547.

Pink, R. C., Bailey, T. A., Iputo J. E., Sammon, A. M., Woodman, A. C., \& Carter, D. R. F. (2011). Molecular basis for maize as a risk factor for esophageal cancer in a South African population via a prostaglandin E2 positive feedback mechanism. Nutr Cancer, 63(5), 714-21. https://doi.org/10.1080/01635581.2011.570893

Pritchett, N. R., Murphy, G., Etemadi, A., Burgert, S. L., Abnet, C. C., Dawsey, S. M., \& Mwachiro, M. M. (2017). High urine polycyclic aromatic hydrocarbon concentrations in Bomet County, Kenya, a region with a high incidence of esophageal squamous cell carcinoma. $J$ Global Oncol. https://doi.org/10.1200/JGO.2017.009464

Purchase, I. F. H., Tustin, R. C., \& van Rensburg, S. J. (1975). Biological testing of food grown in the Transkei. Fd Cosmet Toxicol, 13, 639-647. https://doi.org/10.1016/0015-6264(75)90154-6

Qiao, Y. L., Dawsey, S. M., Kamangar, F., Fan, J. H., Abnet, C. C., Sun, X. D., ... Taylor, P. R. (2009). Total and cancer mortality after supplementation with vitamins and minerals: follow-up of the General Population Nutrition Intervention Trial. J Natl Cancer Inst, 101(7), 507-518. https://doi.org/10.1093/jnci/djp037

Rokkas, T, Pistolias D., Sechopoulos, P., Robotis, I., \& Margantinis, G. (2007). Relationship between Helicobacter pylori infection and esophageal neoplasia: A meta-analysis. Clin Gastroenterol Hepatol., 5, 1413-1417. https://doi.org/10.1016/j.cgh.2007.08.010

Rose, E. F. (1978). The role of demographic risk factors in carcinogenesis. In H. E., Nieberg, \& M., Decker (Eds.), Prevention and detection of cancer. New York.

Rose, E. F. (1979). Epidemiology of oesophageal cancer in Southern Africa. Adv Med Oncol Res Ed., 9, 317-326.

Rose, E. F. (1982). Esophageal cancer in Transkei - the pattern and associated risk factors. In Pfeiffer (Ed.), Cancer of the Oesophagus. Florida: CRC Press.

Rose, G. (2001). Sick individuals and sick populations. Int $J$ Epidemiol, 30, 427-432. https://doi.org/10.1093/ije/30.3.427

Roshandel, G., Semnani, S., Malekzadeh, R., \& Dawsey, S. M. (2012). Polycyclic aromatic hydrocarbons and esophageal squamous cell carcinoma - a review. Arch Iran Med, 15(11), 713-722.

Rossi, M., Ancona, E., Mastrangelo, G., Solimbergo, D., Paruzzolo, P., Azzarini, G., ... Peracchia, A. (1982). Rilievi epidemiologici sul cancro esofageo nella Regione Veneto. [Epidemiological surveys on esophageal cancer in the Veneto region.] Minerva Medica, 73, 1531-1540. Italian

Roth, M. J., Strickland, K. L., Wang, G. Q., Rothman, N., Greenberg, A., \& Dawsey, S. M. (1998). High levels of carcinogenic polycyclic aromatic hydrocarbons present within food from Linxian, China may contribute to that region's high incidence of oesophageal cancer. Eur $J$ Cancer, 34(5), 757-758. https://doi.org/10.1016/S0959-8049(97)10071-5

Sammon, A. M. (1992). A case-control study of diet and social factors in cancer of the esophagus in Transkei. Cancer, $\quad 69, \quad 860-65 . \quad$ https://doi.org/10.1002/1097-0142(19920215)69:4<860::AIDCNCR282069 0404>3.0.CO;2-Y

Sammon, A. M., \& Iputo, J. E. (2006). Maize meal predisposes to endemic squamous cancer of the oesophagus in Africa: breakdown of esterified linoleic acid to the free form in stored meal leads to increased intragastric PGE2 production and a low-acid reflux. Med Hypotheses, 67, 1430-1435. https://doi.org/10.1016/j.mehy.2006.05.037

Sammon, A. M. (1999). Maize meal, non-esterified linoleic acid, and endemic cancer of the esophagus preliminary findings. Prostaglandins and other lipid mediators, 57(2-3), 167-71. https://doi.org/10.1016/S0090-6980(99)00006-4

Sammon, A. M. (2009). Squamous cancer of the oesophagus in Africa. Retrieved from www.scoafrica.org

Sammon, A. M., Mguni, M., Mapele, L., Awotedu, K. O., \& Iputo, J. E. (2003). Bimodal distribution of fasting gastric acidity in a rural African population. South Afr Med J, 93(10), 786-8.

Sammon, A. M., \& Ndebia, E. J. (2019). Aetiology of Oesophageal Cancer in Africa - A Review of Historical and Current Evidence. Global J Health Sci, 11(12), 91-108. https://doi.org/10.5539/gjhs.v11n12p91

Sammon, A. M., \& Whittington, F. M. (2009). Storage releases physiologically active content in milled maize and wheat. Afr J Fd Sci., 3(12), 426-428. https://doi.org/10.5897/AJFS.9000273 
Schaafsma, T., Wakefield, J., Hanisch, R., Bray, F., Schuz, J., Joy, E. J. M., ... McCormack, V. (2015). Africa's oesophageal cancer corridor: Geographic variations in incidence correlate with certain micronutrient deficiencies. PLoS ONE. https://doi.org/10.1371/journal.pone.0140107

Schepp, W., Steffen, B., Ruoff, H. J., \& Schusdziarra, V. Classen M. (1988). Modulation of rat gastric mucosal prostaglandin E2 secretion and stress-induce mucosal damage. Gastroenterology, 95(1), 18-25. https://doi.org/10.1016/0016-5085(88)90285-5

Segal, I., Reinach, S. G., \& de Beer, M. (1988). Factors associated with oesophageal cancer in Soweto, South Africa. Br J Cancer, 58, 681-6. https://doi.org/10.1038/bjc.1988.286

Sewram, V., Sitas, F., O'Connell, D., \& Myers, J. (2014). Diet and esophageal cancer risk in the Eastern Cape Province of South Africa. Nutrition and Cancer, 666(5), 799. https://doi.org/10.1080/01635581.2014.916321

Sewram, V., Sitas, F, O'Connell, D., \& Myers, J. (2016). Tobacco and alcohol as risk factors for oesophageal cancer in a high incidence area in South Africa. Cancer Epidemiology, 41, 113-121. https://doi.org/10.1016/j.canep.2016.02.001

Somdyala, N. I. M., Parkin, D. M., Sithole, N., \& Bradshaw, D. (2014). Trends in cancer incidence in rural Eastern Cape Province, South Africa 1992 - 2012. Int J Cancer, 136, E470-E474. https://doi.org/10.1002/ijc.29224

Uno, K., Iijima, K., Hatta, W., Koike, T., Abe, Y., Asano, N., ... Shimosegawa, T. (2011). Direct measurement of gastroesophageal reflux episodes in patients with squamous cell cancer by 24-h $\mathrm{pH}$-impedance monitoring. Am J Gastroenterol, 106, 1923-1929. https://doi.org/10.1038/ajg.2011.282

van Rensburg, S. J. (1979). Demography of oesophageal cancer in Transkei. In: Environmental associations with oesophageal cancer in Transkei. The National Cancer Association of South Africa and the South African Medical Research Council.

van Rensburg, S. J. (1981). Epidemiologic and dietary evidence for a specific nutritional predisposition to esophageal cancer. J Natl Cancer Inst., 617, 243-251. https://doi.org/10.1093/jnci/67.2.243

van Rensburg, S. J., Bradshaw, E. S., Bradshaw, D., \& Rose, E. F. (1985). Oesophageal cancer in Zulu men, South Africa: A case-control study. Br J Cancer., 51, 399-405. https://doi.org/10.1038/bjc.1985.54

Wang, A., Zhu, C., Fu, L., Wan, X., Yang, X., Zhang, H., ... Zhao, H. (2015). Citrus fruit intake substantially reduces the risk of esophageal cancer. Medicine, 94(39), 1-10. https://doi.org/10.1097/MD.0000000000001390

Wang, S. M., Taylor, P. R., Fan, J. H., Pfeiffer, R., Gail, M. H., Liang, H., ... Abnet, C. C. (2017). Effects of vitamin and mineral supplementation on total and cancer mortality (Linxian General Population Randomised Nutrition Intervention Trial): results from the 25-year post-trial follow-up. The Lancet. 390(Supp 4), S20. https://doi.org/10.1016/S0140-6736(17)33158-6

Weber, E. J. (1969). Lipids of maturing grain of corn (Zea mays L): I. Changes in lipid classes and fatty acid composition. J Am Oil Chem Soc, 46(9), 485-88. https://doi.org/10.1007/BF02544374

World Cancer Research Fund/American Institute for Cancer Research. (2007). Food, Nutrition, physical activity and the prevention of cancer: a global perspective. Washington DC: AICR.

World Cancer Research Fund/American Institute for Cancer Research. (2016). Diet, Nutrition, Physical Activity and Cancer: a Global Perspective. WCRF/AICR.

Yamaji, T., Inoue, M., Sasazuki, S., Iwasaki, M., Kurahashi, N., Shimazu, T., \& Tsugane, S. Japan Public Health, Center-based Prospective Study Group. (2008). Fruit and vegetable consumption and squamous cell carcinoma of the esophagus in Japan: the JPHC study. Int $J$ Cancer, 123(8), 1935-1940. https://doi.org/10.1002/ijc.23744

Yang, C. X., Wang, H. Y., Wang, Z. M., Du, H. Z., Tao, D. M., Mu, X. Y., ... Tajima, K. (2005). Risk factors for esophageal cancer: a case-control study in South-western China. Asian Pac J Cancer Prev., 6(1), 48-53.

\section{Copyrights}

Copyright for this article is retained by the author(s), with first publication rights granted to the journal.

This is an open-access article distributed under the terms and conditions of the Creative Commons Attribution 
license (http://creativecommons.org/licenses/by/4.0/). 